\title{
Sociologia do majestoso: uma análise interseccional do clássico do futebol paulista
}

Larissa Serpentini Souza ${ }^{1}$

\section{RESUMO}

Essa análise pretende discutir de forma interseccional, as dinâmicas sociais de formação dos clubes de futebol profissional S. C Corinthians Paulista e São Paulo F. C. O clássico jogo entre os dois clubes é popularmente conhecido como majestoso, e este jogo, além de significar muito para os amantes de futebol, tem muito a contribuir para análises sociológicas de como um esporte tão popular e abrangente ainda constitui um espaço privado, elitizado, racista e sexista. Desta forma, se sobrepõe aqui identidades sociais com histórico de opressão: classe, raça e gênero dentro da realidade do futebol, sendo tomados como exemplos os dois clubes citados e contribui com uma charge de autoria própria.

Palavras-chave: Interseccional; Futebol; Majestoso; Sociologia.

\begin{abstract}
This analysis intend to discuss within an intersectional form, the social dynamics in the formation of professional football clubs S. C. Corinthians Paulista and São Paulo F. C. The classic between them is popularly known as majestic, and this match, besides meaning a lot for the lovers of football, also has so much to contribute to sociological analysis of how a popular and comprehensive sport still constitutes a private, elitist, racist and sexist space. In this way, social identities with a history of oppression overlap: class, race and gender within the reality of football, being taken as examples the two clubs mentioned and contributions of my own authorship.
\end{abstract}

Keywords: Intersectional; Football; Majestic; Sociology.

\footnotetext{
${ }^{1}$ Estudante da graduação em Geografia pela Universidade Estadual de Campinas. E-mail: larissa_serpentini@outlook.com.
} 
$\mathrm{O}$ futebol, além de ser um patrimônio cultural do Brasil e um dos esportes mais populares no mundo, é também um ambiente extremamente complexo e fonte para diversas análises sociais caso seja observado por outras perspectivas que vão além do esporte em si, pois se trata de um fenômeno mundial de massas e que agrupa vários elementos sociais.

No entanto hoje, o futebol significa um novo ramo para o mundo dos negócios, se adentrando ao setor econômico, fazendo com que deixe de ser apenas um esporte e passe a envolver outras questões, assim, a prática e também o consumo de bens e/ou atividades ligadas ao futebol profissional só é possível graças a uma cadeia de atividades econômicas que encontram no esporte, o ambiente ideal para investimentos.

Alguns estudos já se debruçam sobre essa temática para analisar os impactos econômicos do futebol e a proporção que tem tomado neste aspecto. Para se ter uma ideia, segundo o relatório final do Plano de Modernização do Futebol Brasileiro (200o) da Fundação Getúlio Vargas (FGV), os dados econômicos do futebol brasileiro, que envolvem desde patrocínios e direitos televisivos (empresas de comunicação), até a produção de bens de consumo são bastante expressivos:

os fluxos monetários que compõem o setor futebol nacional somam $\mathrm{R} \$ 3,5$ bilhões anuais. Tais fluxos são fortemente concentrados nas entidades do futebol, especialmente nos clubes, cuja produção é responsável por mais de $\mathrm{R} \$ 2,1$ bilhões anuais, com participação significativa também das empresas de comunicação, com produção estimada em $\mathrm{R} \$ 910$ milhões anuais. (FGV, 200o). 
No entanto, pode-se observar que a atividade econômica não chegou somente ao ambiente empresarial e político dos clubes, mas também aos gramados, aos estádios luxuosos e modernizados, e aos preços dos ingressos, fazendo com o que antes era o exercício de uma paixão, se torne fonte de enriquecimento para quem nada tem a ver com o futebol em sua mais romântica definição. Esse adentramento do capital no meio futebolístico não é necessariamente o foco desta análise, entretanto o tema é imprescindível para o desenrolar dessa linha de pensamento, que pretende estudar opressões sociais que são extremamente agravadas por conta desse processo. Tomamos para isso a ideia de interseccionalidade, na qual o capital e o acesso ao capital permeia a discussão e nos ajuda a entender e nos aprofundar nos dilemas que envolvem o clássico Majestoso entre Corinthians e São Paulo do ponto de vista social, desta forma, a intersecção entre classe, raça e gênero serão fundamentais para embasar todo o raciocínio.

A interseccionalidade ${ }^{2}$ tem gerado debate importante, principalmente nas discussões a respeito de pesquisas em gênero, entendendo que a sobreposição entre as parcelas sociais é extremamente necessária, visto que se entrelaçam e, assim, explicam as injustiças sociais. Patrícia Hill Collins, renomada pesquisadora norte-americana e referência no estudo do feminismo negro, coloca a interseccionalidade, dentre outras características, como uma forma de investigação crítica, sendo uma importante corrente com capacidade de emancipação das forças de opressão por parte das grandes e poderosas instituições sociais, que busca a reivindicação de reparações históricas e justiça social:

A eficácia das ideias centrais de interseccionalidade, em situações díspares politicamente, levanta questões

2 Para maior compreensão do termo indica-se texto de Helena Hirata: "Gênero, classe e raça: Interseccionalidade e consubstancialidade das relações sociais". Vide referências bibliográficas. 
importantes sobre a relevância do conhecimento para a luta por liberdade e iniciativas de justiça social (COLLINS, 2017).

Uma outra ótica da interseccionalidade que buscamos trabalhar nessa análise é o âmbito político-econômico, tal como trabalha Nancy Fraser, colocando essas formas de opressão numa dimensão culturalavaliativa, ou seja, problemas na distribuição e no reconhecimento de certas categorias em detrimento de outras. Dessa forma, a interação entre esses aspectos, confluem e são bastante explicados por essa relação política, econômica e cultural, que julgamos o futebol fazer parte. Essa visão é bastante relevante para essa análise, pois tenta entender as relações existentes entre classe, raça e gênero com o futebol como plano de fundo, sendo retratado do ponto de vista econômico e também político, buscando estabelecer explicações para as problemáticas existentes, gerando debate e se colocando como uma voz dessas populações rejeitadas nesse meio.

\section{Gênero}

Dentro do futebol, a discussão acerca de raça e classe não é, de fato, tão conhecida como a discussão de que o ambiente desse esporte é misógino e muitas vezes brutal com sujeitos que fujam do padrão homem heterossexual, este é um assunto no qual as relações são extremamente díspares e nítidas; nesse sentido, o futebol (não só o brasileiro) muitas vezes já se mostrou para nós como pode ser intolerante.

As relações sexistas estruturam o futebol desde sua gênese, e dentre os agentes mais afetados nesse sentido seriam o que chamou 
Spivak ${ }^{3}$ de sujeito subalterno, em seu livro: "Pode o subalterno falar?". Embora não seja ela a autora desse conceito, a mesma faz uma importante análise acerca das mulheres subalternas, as quais seriam, para ela, mulheres de regiões periféricas, não ocidentais. É interessante essa análise, pois se encaixa muito bem nessa discussão, sendo assim, poderíamos nos indagar: dentro do futebol quem seriam os sujeitos subalternos? As mulheres com certeza; elas se encontram entre os sujeitos mais subalternos do ambiente, não somente sofrem com isso as mulheres heterossexuais, pois mais subalternos ainda se encontram transgêneros, homossexuais e toda a comunidade LGBTQ+. Nesses casos, a visibilidade é ainda menor, quase inexistente, como que se o espaço desse esporte de maneira alguma pudesse ser utilizado por essas populações.

A análise interseccional se faz necessária aqui, pois quando tratamos de mulheres negras e pobres, as relações se mostram muito mais opressivas e nítidas, nas quais sexismo e racismo se entrelaçam (ambos nascem dos supostos argumentos biológicos). Essa discussão tem sido muito importante para explicar as opressões sociais vivenciadas por esses grupos historicamente, (e também, neste caso, no futebol).

A relação entre racismo e sexismo no futebol é bastante clara, no qual se pode notar que rostos femininos negros são minoria, quase ausentes nos estádios, tais como mulheres negras que trabalham no ambiente esportivo, como o jornalismo. Essas relações, tais como Nancy Fraser as coloca, com um âmbito político e econômico, se sobrepostas às discussões de classe, nos explicam muito sobre o porquê dessas ausências, onde as mesmas não possuem o mesmo reconhecimento, oportunidades de trabalho e geração de renda que os homens, homens brancos e negros, e até de mulheres brancas, ficando em situações

${ }^{3}$ Gayatri Chakravorty Spivak é uma crítica e teórica indiana, mais conhecida por seu livro "Can the Subaltern Speak?", considerado um texto fundamental póscolonial. 
trabalhistas bastante delicadas. Dessa forma, o futebol para essa parcela social é um ambiente extremamente hostil e de difícil acesso.

Se tratando de clássico majestoso (Corinthians e São Paulo), essa intolerância e misoginia é ainda mais clara, no entanto passa muitas vezes como "parte da cultura do esporte" pois os torcedores costumam utilizar de nomes pejorativos para se referir a torcida adversária, como bem explica Maurício Rodrigues Pinto:

ao se referir ao Corinthians como "Galinha", no futebol, simboliza covardia e fraqueza em momentos decisivos e, no caso da rivalidade entre São Paulo e Corinthians, pode ser entendida como uma feminização do gavião, ave símbolo da principal torcida organizada do Corinthians, a Gaviões da Fiel. "Galinha" também é uma estratégia de torcedores sãopaulinos para responder ao "bambi", ofensa usada para associar o São Paulo e sua torcida à homossexualidade. O apelido se popularizou no final da década de 1990, quando o ex-jogador corintiano Vampeta falou para jornalistas que "bambi" era a forma como ele se referia aos seus colegas que jogavam pelo São Paulo, justamente por não terem uma performance considerada condizente com a de um "boleiro" (PINTO, 2017).

Dessa forma, as "performances” esperadas pelos jogadores de futebol e, consequentemente, a sua torcida se espelham nas chamadas noções de masculinidade, que formam a identificação de gênero que são construídos e reproduzidos socialmente; noções essas que nada têm a ver com mulheres, ou seja, nada que chegue próximo ao que é considerado pertencente ao gênero feminino é aceito como parte do meio do futebol, assim, tudo que possa ser assemelhado ao feminino é propositalmente exclúido, como forma de humilhação e vergonha.

É fato que esse sexismo não é exclusivo das torcidas desses clubes citados, isso é uma realidade do futebol mundial, não só o brasileiro. As mulheres ainda não são entendidas e colocadas como parte do esporte e, quando são colocadas, a valorização tanto profissional quanto salarial para as jogadoras e valorização e igualdade social para as 
torcedoras ainda são extremamente abissais. Nos clubes paulistas aqui analisados, ambos possuem a repartição de futebol feminino, no entanto com patrocínios e divulgação muito menores que o masculino. Por exemplo, a título de curiosidade, o Corinthians só fundou uma equipe de futebol feminino no ano de 2016, em parceria com outro clube (Grêmio Osasco Audax) e o time ficou oficialmente independente somente em 2018. (Fonte: Meu timão).

Um exemplo bem conhecido é a amplitude salarial entre a jogadora Marta (Orland Pride) e o jogador Neymar (Paris Saint Germain), ambos brasileiros, a diferença é esmagadora, mesmo com as diversas premiações mundiais da atleta, as quais Neymar ainda não alcançou. A recente lista divulgada pela revista France Football (2019) apontou que o jogador brasileiro possui um salário (tirando bônus e outros rendimentos) mais de 140 vezes maior que o de Marta. (FERA, 2019).

Mesmo com toda essa disparidade salarial, surgem tentativas de argumentos que anulam a questão de gênero para explicar o fenômeno, como a de que Marta não atrai patrocinadores e público em relação ao jogador, mas ora, é impossível não relacionar o gênero a essa desproporcionalidade: Marta não gera o mesmo lucro em cima de patrocínios e público pelo fato de o futebol feminino como um todo não ser valorizado, divulgado e nem receber apoio como o masculino, pois como já ressaltamos, as jogadoras não são colocadas no mesmo nível competitivo do esporte. Dessa forma, a colocação de que essa diferenciação de valores tanto sociais como econômicos não é explicada pelo gênero é extremamente rasa e sexista, de modo que anula todo o histórico de opressão e anulação vivido pela parcela feminina dentro desse ambiente. 


\section{Classe}

Para começar a compreender como o meio futebolístico é um ambiente propício a este tema é necessário entender que a história do futebol brasileiro existente é também a história da luta de classes, parafraseando Marx ${ }^{4}$. A história do futebol brasileiro é desde os seus primórdios fruto dessa diferenciação, pois a sua chegada ao Brasil só se deu por esse meio: Charles Miller tido como o precursor do futebol no Brasil, homem, branco e desde muito jovem socializado na Inglaterra (o que é algo do caráter de famílias com rendas acima do nível básico de sobrevivência), trouxe o esporte para o país, não que essas formas de lazer já não fossem conhecidas em outras localidades e por outras culturas, mas Charles, como homem universalmente aceito pôde deixá-lo de certa forma normatizado.

Tendo em vista que o futebol brasileiro pode ser analisado do ponto de vista dos antagonismos e contradições de classes, propõe-se analisar a história de formação desses clubes que representam, em certa medida (ou o que mais podem exemplificar), o que o sociólogo brasileiro Jessé Souza coloca como Ralé e Elite, não que as torcidas representam em sua totalidade essas classes, literalmente como as coloca Jessé, mas sim, como os preconceitos e distinções de classe se sentem melhor acomodados em cada torcida. A título de embasamento geral, para ele, a ralé se caracteriza da seguinte forma:

[...] uma classe inteira de indivíduos, não só sem capital cultural nem econômico em qualquer medida significativa, mas desprovida, esse é o aspecto fundamental, das precondições sociais, morais e culturais que permitem essa apropriação. É essa classe social que designamos neste livro de "ralé" estrutural, não para "ofender" essas pessoas já tão sofridas e humilhadas, mas para chamar a atenção,

\footnotetext{
${ }^{4}$ MARX, K., ENGELS, F. Manifesto do Partido Comunista: "A história de todas as sociedades até hoje existentes é a história da luta de classes"
} 
provocativamente, para nosso maior conflito social e político: o abandono social e político, "consentido por toda a sociedade", de toda uma classe de indivíduos "precarizados" que se reproduz há gerações enquanto tal. (SOUZA, 2011).

Dessa forma, as classes médias e as elites seriam as classes que, ao contrário da ralé, gozam de privilégios estruturais em decorrência das condições familiares em que nascem, ou mais precisamente, são socializados em circunstâncias de acesso ao capital, que por sua vez, dá acesso a melhor educação, cultura e oportunidades, muito melhores do que a ralé.

Essas disparidades econômicas, que dão origem às diferenciações de classe, ocorrem como Fraser coloca, na desigualdade dos reconhecimentos, no sentido de valoração cultural, e também das más distribuições, no entanto podendo uma ocorrer sem a outra como cita o exemplo de um trabalhador formal, homem branco, que perde o emprego por conta da fábrica fechar ou ir a falência:

\footnotetext{
Nesse caso, a injustiça da má distribuição tem pouco a ver com o não reconhecimento. Ela é muito mais uma conseqüência dos imperativos intrínsecos a uma ordem de relações econômicas especializadas cuja raison d'être é a acumulação de lucros (FRASER, 2007).
}

Tendo todo esse embasamento inicial em mente, desejamos aqui entender como as contradições de classe, tal como as conceitualiza Jessé, possuem uma relação de base para as opressões de sexismo e racismo, pois se colocam como um pilar essencial para que essas problemáticas se fortaleçam. Embora a teoria levantada por Fraser seja extremamente mais complexa e mais abrangente que o que colocamos aqui, entendemos que a relação entre os conceitos de distribuição e reconhecimentos se encaixam e conversam muito bem com as contradições e problemáticas de classe, visto que os reconhecimentos culturais em relação às classes mais baixas é diferente das mais altas. 


\section{Raça}

Nesse ponto, é importante ter em mente que o racismo está estruturalmente e historicamente ligado à história do Brasil, sendo o país que aboliu a escravidão por último na América Latina, e que historicamente demorou, e muito, para iniciar políticas de inserção dessa população na vida pública, política e social do país. Assim, a população negra foi submetida anos após anos ao que há de pior, com poucas iniciativas de assistência por parte do Estado, e hoje se configuram como apenas $17,4 \%$ da parcela mais rica da população, sendo que são $54 \%$ da população brasileira, segundo dados do IBGE de 2015.

Embora a discriminação racial no Brasil não seja mais institucionalizada por Lei como outrora, as formas de opressão ainda fazem parte do cotidiano da população negra no país, originada em nosso passado escravocrata. No livro "Brasil uma biografia", Lilia Moritz Schwarcz e Heloísa Murgel Starling abrem um parecer a respeito disso:

Apesar de não existirem formas de discriminação no corpo da lei, os pobres e sobretudo as populações negras são ainda mais culpabilizados pela justiça, os que morrem mais cedo, têm menos acesso à educação superior pública ou a cargos mais qualificados no mercado de trabalho. (SCHWARCZ; STARLING, 2015).

Uma sociedade que fora marcada pela desigualdade desde seus primórdios, o Brasil tentou se mostrar por muito tempo como uma democracia racial, na tentativa da Elite brasileira pós 1920 minimizar o passado e a origem miscigenada do nosso povo, como se nossa mistura de raças fosse um fator importante para o tão desejado desenvolvimento, observa Marcelo Paixão, citado por Carlos Haag, em sua entrevista com Lillia Schwarcz “Quase pretos, quase brancos”: 
Passado o secular período do escravismo, entre 1890 e 1920 , a elite brasileira se debateu com a angústia quanto às origens genéticas mestiças de nosso povo e de sua capacidade de servir de base para o tão sonhado desenvolvimento econômico, político e cultural. Balizados na interpretação racista, postas as origens mestiçadas do povo brasileiro, seríamos incapazes ao desenvolvimento e ao progresso (PAIXÃO. In: HAAG. 2007).

Dessa forma, visando "explicar" a discriminação racial existente, os intelectuais da época buscaram, através de modelos científicos, mostrar como a questão no país era cultural, nasce então o "racismo a brasileira”, como denomina Lilia Schwarcz.

No entanto, é inegável que as marcas do período da escravidão institucional no país se prolongam, fazendo parte do cotidiano da população negra no país, que sofre com o racismo e a violência com dados alarmantes, onde hoje a cada 23 minutos um jovem negro é assassinado no Brasil. A situação se agrava se colocada em perspectiva a questão de gênero, "Uma menina negra, por sua vez, tem duas vezes mais chances de morrer do que uma menina branca." (ONU, 2019). Além da violência, a sexualização do corpo feminino negro é outra forma de opressão vivenciada. Na cultura as representações sexistas variam desde a literatura até as produções cinematográficas:

Já é uma discriminação duplicada. Não é a dupla jornada de trabalho, mas é a dupla jornada de preconceito, porque se existe um leque de representações negativas com relação ao malandro, ao mestiço, quando se refere à mulher, isso aumenta.A mulata é palco para a idéia de que não é só a preguiça, mas os atos sexualmente condenáveis; há a influência da prostituição, a traição, a mulata que é matreira (SCHWARCZ apud HAAG. 2007).

Assim, partindo dessa discussão a respeito das discriminações de gênero, classe e raça no Brasil, pretendemos entender como as origens desses processos podem ser encontradas no contexto geográfico e social da formação dos dois clubes paulistanos, Sport Club Corinthians Paulista 
e São Paulo Futebol Clube. Os quais, embora sejam pertencentes à mesma localidade urbana, representam relações sociais com o espaço extremamente diferentes, e apresentam em si relações de classe muito claras e distintas entre si, mas que ao mesmo tempo compartilham do problema da elitização dos espaços esportivos e das relações racistas e sexistas no futebol.

\section{Contextos geográficos de formação dos clubes e seus simbolismos de classe}

\section{1) Sport Club Corinthians Paulista}

A história de fundação deste clube nos ajuda a entender, e muito, o porquê de hoje o clube ser considerado o time do povo, e muitos outros apelidos que o clube recebe, além de aqui, ser relacionado com a classe ralé, ou ainda, proletária.

A explicação se remete ao fato desse clube ter sido criado em 1910 por um grupo de operários que trabalhavam na região do bairro Bom Retiro, em São Paulo, o qual foi um bairro extremamente bem localizado em relação às fábricas que estavam se instalando em grandes quantidades nesse período. Logo que fora criado, um dos lemas colocados pelos operários foi de que "O Corinthians vai ser o time do povo e o povo é quem vai fazer o time"5. Além desse clube ser fundado em uma região (à época) não muito valorizada - inclusive era muito conhecida como uma região de prostituição - o contexto pelo qual ele foi criado também explica muito.

O fato do time ser fundado por operários, chãos de fábrica, proletários, configurou ao time apelidos pejorativos, e que muito tem a Battaglia.

${ }^{5} \mathrm{O}$ autor da frase foi o presidente escolhido pelos operários, o alfaiate Miguel 
ver com essa origem pobre: sempre relacionados ao roubo, ao sujeito "vagabundo" e à favela. Por exemplo, com uma rápida pesquisa online sobre como "ofender" o torcedor Corintiano é fácil se deparar com frases como estas: Corintiano com uniforme $=$ Porteiro; Corintiano com maleta = Office-Boy; Corintiano com sandálias = Mendigo; Corintiano lendo jornal $=$ Desempregado; Corintiano se coçando = Sarnento; Corintiano correndo = Ladrão; Corintiano subindo morro = Voltando para casa; Corintiano bem vestido = Estelionatário ou Presidente da República; Corintiano coçando a cabeça = Piolhento; Corintiano parado na rua $=$ Suspeito.

Repare que a forma de hostilizar o rival (aqui o Corinthians), sempre se volta para a questão de classe, sempre se relaciona a profissões não bem pagas e não prestigiadas, ao roubo, a sujeira e a suspeita de algo; não é muito parecido com os estigmas sociais colocados sobre as classes mais baixas da nossa sociedade? Essas frases estão relacionadas de forma a se referir à torcida do Corinthians, a torcida do povão, das classes baixas, como ao que há de ruim na sociedade, a ralé, com origem no fato de o clube ter sido fundado numa região caracterizada por famílias operárias e de baixa renda.

\section{2) São Paulo Futebol Clube}

De forma antagônica à fundação do rival, o São Paulo F.C - antes mesmo de receber esse nome - era denominado de Clube Atlético Paulistano, foi fundado numa das zonas mais nobres da cidade, na Rotisserie Sportsman (Rua São Bento, no 61), em 29 de dezembro de 1900, em parceria com outro clube amador AA das Palmeiras (que foi fundado em 9 de novembro de 1902 e sediado inicialmente na Av. Angélica, Santa Cecília, numa região de grandes casarões e de famílias nobres da capital paulistana), em um período que o futebol era 
tradicionalmente jogado por famílias de imigrantes europeus. Um fato curioso do Paulistano é que um dos ideais do clube era que "Para o Paulistano, o jogador deveria vestir a camisa por paixão, por fidelidade, sendo sócio do clube. Ou seja, na prática, deveria pagar ao clube, e não o contrário”, (Site Oficial SPFC). É curioso, pois o fato de não receber dinheiro para exercer essa carreira simboliza que o dinheiro não era de fato uma necessidade desses que o criaram, ou que no mínimo era indiferente. Outro detalhe é que de forma totalmente oposta a fundação operária do Corinthians, o São Paulo FC foi fundado oficialmente com esse nome por sócios dos dois clubes amadores, e, para ser sócio, é necessário influência e dinheiro, coisa que a ralé nunca possuiu.

\section{Os estádios}

Outro ponto crucial que serve para termos uma ideia da diferenciação desses clubes se remete à localização de seus estádios. $\mathrm{O}$ São Paulo, tradicionalmente desde 196o, possui o estádio Cícero Pompeu de Toledo, o Morumbi, que fica em uma zona muito nobre da cidade de São Paulo, conhecido por seus entraves fortificados e residências luxuosas.

De forma até certo modo ilustrativa de moradia do "povo", o Corinthians utilizou como seu estádio, por algum tempo, o Parque São Jorge e "pagou aluguel" no Estádio Municipal Paulo Machado de Carvalho, o Pacaembu, por muitos anos, até que enfim, o estádio oficial do Corinthians só foi inaugurado em 2014, em Itaquera, zona leste de São Paulo.

Embora hoje ambos sejam luxuosos e exista pouca diferença entre eles em relação a construção (sendo o do Corinthians mais novo e, portanto, mais conservado), a localização é o que nos importa aqui, por 
representarem regiões opostas tanto geograficamente quanto socialmente.

No sentido das localizações geográficas ambos os clubes se distinguem, no entanto, foram modernizados e possuem valores de ingressos bastante altos, fazendo com que o público que consegue ter acesso aos jogos seja bastante restrito, o que torna o ambiente mais elitizado e, consequentemente, mais "embranquecido", com pouca presença de torcedores negros.

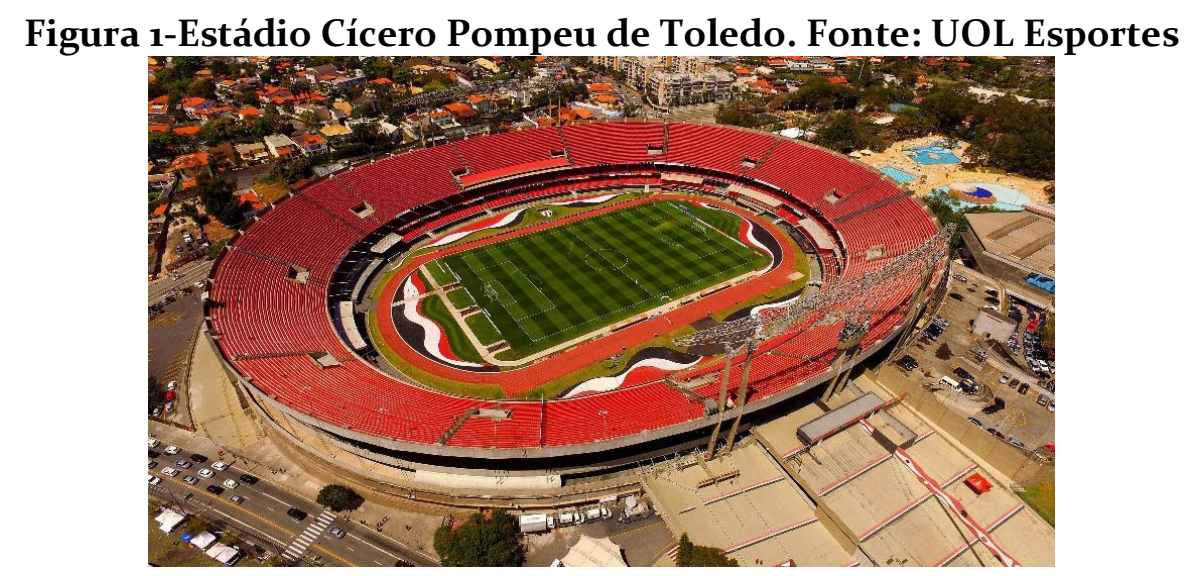

Fonte/foto: Luis Moura/WPP.

Figura 2-Arena Corinthians. Fonte: Revista Época.

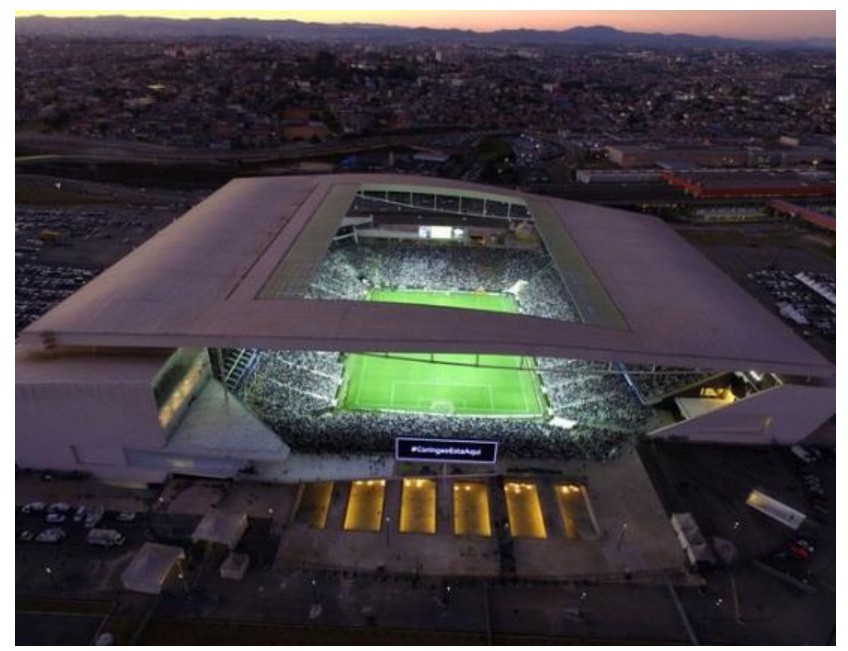

Fonte/foto: Carlos Nardi/WPP/Folhapress. 


\section{Elitização e embranquecimento}

A elitização do futebol é um fato, o futebol se tornou uma empresa, fonte de lucro e até de investimento. Cada vez mais os valores oferecidos aos jogadores que se destacam são maiores e exorbitantes, dando espaço a uma nova fase do futebol brasileiro, que busca se igualar ao patamar Europeu, no entanto, não consegue competir em visibilidade e mesmo tentando equiparar salários acaba perdendo os jogadores mais promissores.

Pois veja, assim que um jogador se destaca nos gramados brasileiros é muito difícil que permaneça jogando por aqui, as condições oferecidas aqui, mesmo de valores altíssimos, não competem com o que é oferecido lá fora, não somente em salário (pois alguns salários de futebol profissional do Brasil ultrapassam salários oferecidos em alguns países Europeus), mas o sonho de se destacar mundialmente só é realidade, ou pelo menos se torna mais acessível, ao participar dos principais campeonatos do mundo, que se concentram na Europa. Assim, o Brasil hoje, tal como a América Latina num geral, é - novamente - colocado em condição de exploração, sem condições de manter um futebol de alto nível como o desejado.

Essa tendência econômica culmina no aumento nos preços dos ingressos, das camisas oficiais, tais como os produtos originais dos clubes, e são sentidos com peso no bolso dos torcedores, chegando à casos de a Justiça ordenar que os valores dos ingressos fossem diminuídos, como ocorreu com o clube carioca Flamengo em 2013, "O juiz declarou abusivo os preços dos ingressos, que até antes desta decisão liminar giravam entre R\$ 250 e R\$ 800 para não sócios-torcedores". (ESTADÃO, 2013).

Tal tendência, ou seja, a modernização seguida de aumento nos valores dos ingressos, continua sendo utilizada por grande parte dos 
clubes tradicionais brasileiros, inclusive dos aqui tratados, avançando para a construção de setores especiais separados dos torcedores comuns. Essa nova lógica econômica do futebol produz distinções de classe muito claras dentro dos estádios brasileiros, como aponta Antonio Holzmeister:

Começaram a ser construídos pavilhões exclusivos, na maior parte das vezes com assentos e cobertura, para os diretores de clube, seus convidados e torcedores de classe média dispostos a pagar um ingresso mais caro, instituindo assim a segregação baseada em diferenças de poder econômico no futebol (HOLZMEISTER, 2005).

Com esse aumento significativo nos valores, o acesso fica restringido as classes mais favorecidas e embora os dois clubes aqui sejam colocados em classes opostas, ambos abrigam em si uma questão que não cabe em determinada classe apenas, que é o racismo estrutural que envolve nossa sociedade. Esse fator pode ser observado primeiro sob a ótica do racismo direto e também do embranquecimento da torcida como consequência da elitização que o esporte vem sofrendo.

Inicialmente, o racismo pôde ser facilmente identificado pelo fato de nos dois primeiros elencos do clube não existir nenhum registro de jogadores negros, como se pode observar nestas fotos retiradas dos acervos dos clubes. 
Figura 3-Elenco do Corinthians nos primeiros anos de formação

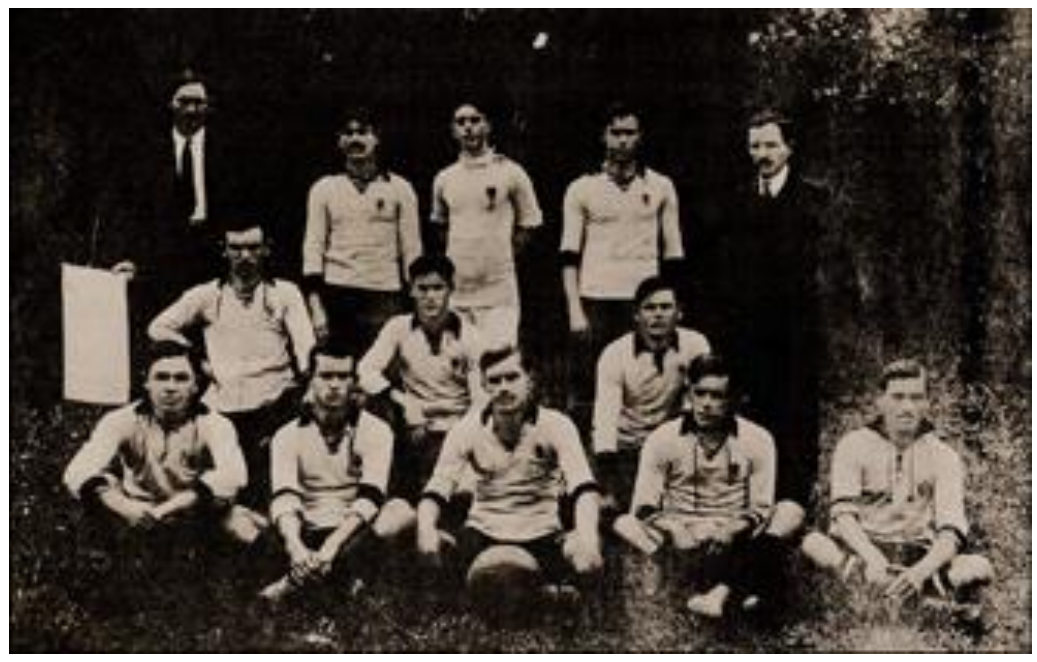

Fonte: Tudo Timão.

Figura 4-Elenco do São Paulo nos primeiros anos de formação

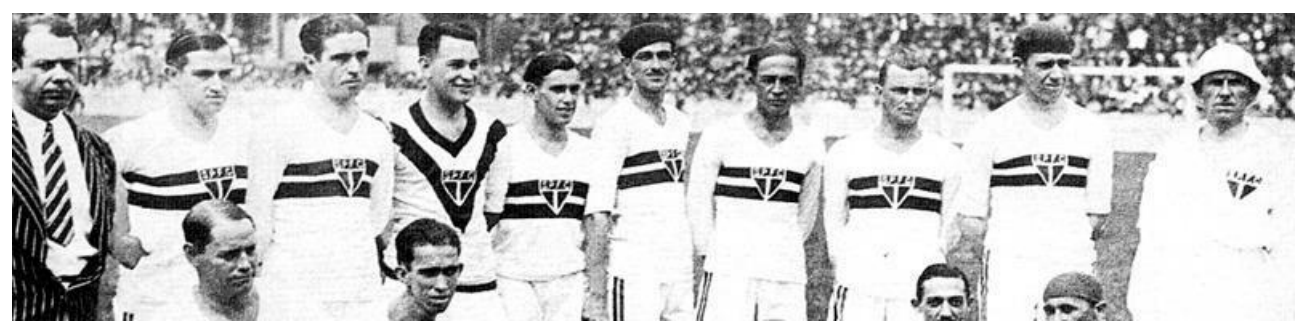

Fonte: Site oficial do clube.

Já o embranquecimento da torcida, colocamos aqui como causa, além do racismo estrutural que violenta a população negra, a elitização do futebol brasileiro e para essa elitização entendemos como principal causa o adentramento do futebol ao setor econômico. Isso é um problema que afeta principalmente as classes mais baixas que por serem sempre desprovidas de acesso à cultura e educação de qualidade são agora também impedidas de frequentar os estádios. Dentre os mais afetados, a população negra, marginalizada socialmente, diminui em quantidade dentro dos estádios, majoritariamente brancos, tornando-se consequentemente, cada vez mais minoria nesse ambiente. Assim, esse embranquecimento da torcida nos estádios é uma forma de exclusão, de 
impedimento do acesso, e mais uma entre tantas formas de violências simbólicas que a população negra e pobre sofre, fruto de um país com um sistema mal abolido de escravidão, como bem coloca Lilia Schwarcz e Heloisa Starling:

[...] a herança da escravidão condiciona até nossa cultura, e a nação se define a partir de uma linguagem pautada em cores sociais. Nós nos classificamos em tons e meios tons, e até hoje sabemos que quem enriquece, quase sempre embranquece, sendo o contrário também verdadeiro (SCHWARCZ, STARLING; 2015).

A contradição se torna ainda mais complexa ao analisarmos como o clube do Corinthians faz uso de termos referentes às classes mais baixas como "povão e favela”, como caracterização do time, ao mesmo tempo em que essas populações são inviabilizadas de ir aos estádios e ficam marginalizadas, destinadas a - quando possível acompanhar seu clube pela televisão.

Esse afastamento das populações periféricas dos estádios se configura um problema parecido com o que acontece nos grandes centros urbanos, onde através de valorização imobiliária da região central os mais pobres são obrigados a procurar novas regiões para moradia, sendo assim, afastados propositalmente dos centros e, consequentemente, de todo acesso à cultura e lazer que se concentram nessas regiões.

A charge abaixo, de produção própria, realiza uma crítica à falta de representatividade nos estádios, com enfoque ao dilema do Corinthians. A figura faz referência a famosa frase "the favela is here", adotada pelo clube na saga de 2012 no Mundial de Clubes da Fifa, que por ser um torneio internacional a língua inglesa foi adotada como forma de se fazer conhecida sua torcida, a favela. 
Figura 5-Charge "The Favela is here"

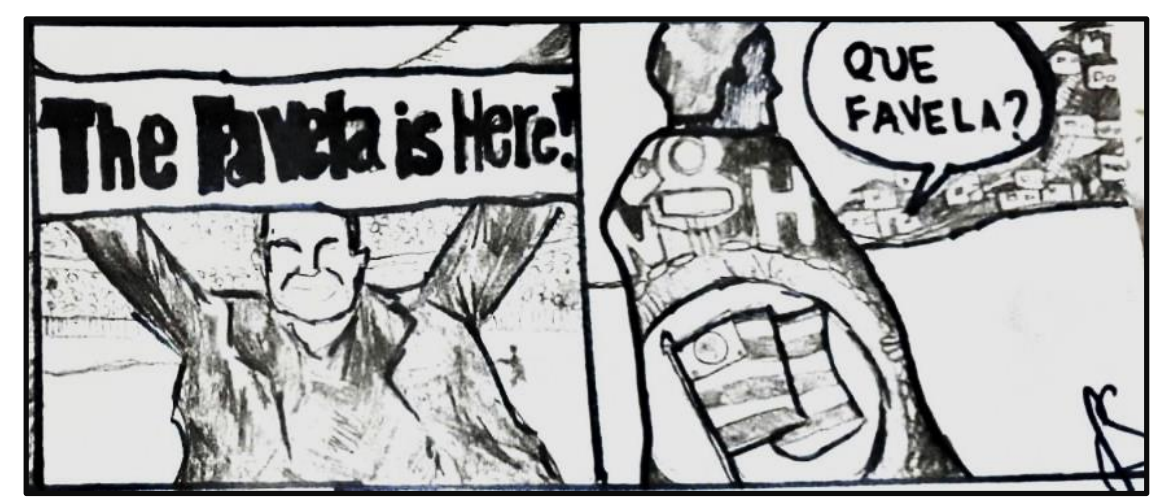

Dessa forma, classe, gênero (de forma intrínseca) e raça são sim uma discussão que os meios esportivos de comunicação e ciência devem estar atentos, buscando contribuir para um novo olhar sobre este esporte que é tão querido nacionalmente. A discussão é importante, pois não podemos deixar que certos comportamentos que não são aceitos socialmente, ou que pelo menos, luta-se diariamente para que deixem de existir, sejam tolerados dentro do futebol com sentimento de naturalização da opressão.

O que aparenta ser nesse caso é de que, pelo fato desse esporte ser totalmente dominado por agentes sociais que não possuem uma história de opressão ele se torne uma "bolha transparente", onde ao mesmo tempo em que aparenta ser para todos e de acesso livre, quando se observa com um olhar mais crítico, pode-se ver como é um ambiente cada vez mais restrito, e como as pessoas impossibilitadas de adentrar a bolha são as mesmas que são diariamente oprimidas socialmente.

Assim, o futebol além de acessível, deveria também ser inclusivo. Só conseguimos enxergar resquícios da classe mais pobre nesse ambiente de luxo e dinheiro quando algum jogador ascende e 
revela suas origens, pois como o futebol é um esporte popular no país, e para ser praticado na sua forma mais simples é necessário apenas uma bola, é o mais popular nas periferias do Brasil, sendo de lá que os principais jogadores de nossa história saíram, e é por isso, dentre outros motivos, que o acesso dessas populações periféricas deve ser livre, pois é ela que há muito tempo sustenta o mercado de grandes jogadores do país.

Dessa forma, encerro a discussão acreditando que esse tema possa gerar diversos outros desmembramentos, na esperança de que o futebol hoje financeirizado se volte para as classes que fizeram este ser o esporte que é hoje para o país, e que o mesmo possa ser de livre acesso aos amantes do futebol.

\section{REFERÊNCIAS}

COLLINS, Patricia Hill. Se perdeu na tradução? Feminismo negro, interseccionalidade e política emancipatória. Tradução Bianca Santana. Parágrafo, v. 5, n. 1 , jan./jun., 2017 ISSN: 2317-4919.

ÉPOCA. Arena Corinthians, a provação alvinegra.Revista Época Disponível em: https://epoca.globo.com/vida/esporte/noticia/2016/o8/arenacorinthians-provacao-alvinegra.html. Acesso em: o1 fev. 2019.

ESTADÃO. Justiça manda Flamengo abaixar preços de ingressos da final da Copa do Brasil. Jornal Estadão. Disponível em: $<$ https://esportes.estadao.com.br/noticias/futebol,justica-mandaflamengo-baixar-precos-de-ingressos-da-final-da-copa-dobrasil,1096729>. Acesso em o1. mar. 2019.

FGV. Relatório final do plano de modernização do futebol brasileiro. Rio de Janeiro : Fundação Getúlio Vargas e Confederação Brasileira de Futebol, 2000. Disponível em: <https://bibliotecadigital.fgv.br/dspace/bitstream/handle/10438/11316/fg vprojetos_caderno_futebol.pdf?sequence $=5$ \&isAllowed $=\mathrm{y}$. 
FRASER, Nancy. Reconhecimento sem ética? Lua Nova, São Paulo, n. 70, p.101-138, 2007.

HAAG, Carlos. Entrevista com Lilia Moritz Schwarcz: Quase pretos, quase brancos. Pesquisa FAPESP, abril de 2007, p.11.

HIRATA, Helena. "Gênero, classe e raça: Interseccionalidade e consubstancialidade das relações sociais". Tempo Social, v. 16, n.1, p. 6173, 2014.

HOLZMEISTER, Antonio. A nova economia do futebol: uma análise do processo de modernização de alguns estádios brasileiros. Antonio Holzmeister Oswaldo Cruz.-Rio de Janeiro: UFRJ/PPGAS, Museu Nacional, 2005.

IBGE. Ibge mostra as cores da desigualdade. Disponível em:<https://agenciadenoticias.ibge.gov.br/agencia-noticias/2012agencia-de-noticias/noticias/21206-ibge-mostra-as-cores-dadesigualdade"noticias/noticias/21206-ibge-mostra-as-cores-dadesigualdade>. Acesso em: 21 nov. 2018.

LEONCINI, Márvio; TERRA, Márcia. Entendendo o futebol como um negócio: um estudo exploratório. Disponível em: <http://arquivo.ufv.br/des/Futebol/artigos/Gest\%C3\%A3o.pdf>. Acesso em 01. fev. 2019.

MARX, K., ENGELS, F. Manifesto do Partido Comunista. São Paulo: Martin Claret, 2000 (1848).

ONU. Campanha de combate a violência contra a juventude negra no Brasil. Dados. Disponível em: <https://nacoesunidas.org/unfpaapoia-campanha-educacional-de-combate-a-violencia-contra-juventudenegra/>. Acesso em o1. mar. 2019).

PINTO, Maurício Rodrigues. "Majestoso” ou o clássico da homofobia vs. misoginia?. 2017. Disponível em: $<$ https://www.ludopedio.com.br/arquibancada/majestoso-ou-o-classicodahomofobia-x-misoginia/> . Acesso em: 15 nov. 2018.

S.C CORINTHIANS. História. Disponível em: <https://www.corinthians.com.br/clube/historia>. Acesso em: 21 nov. 2018. 
SANTOS, Gevanilda. Relações raciais e desigualdade no Brasil. São Paulo: Selo Negro, 2009, p. 1-57.

SÃO PAULO F.C. História. Disponível em: <http://www.saopaulofc.net/spfcpedia/ahistoria-do-spfc/floresta>. Acesso em: 21 nov. 2018.

SCHWARCZ, Lilia; STARLING, Heloisa. Brasil uma biografia. $1^{\circ}$ Ed. Companhia das Letras, São Paulo. 2015.

SOUZA, Jessé. A ralé brasileira quem é e como vive. Rio de Janeiro: Leya, 2011.

SP BAIRROS. Bom Retiro. Disponível em: <http://www.spbairros.com.br/bom-retiro/>. Acesso em 20 dez. 2018.

SPIVAK, Gayatri Chakravorty. Pode o subalterno Falar? Editora UFMG, 2010.

TUDO TIMÃO. Uol. A fundação do Corinthians. 2014. Disponível em: $<$ http://tudotimao.com.br/news.asp?nID=76013>. Acesso em: $20 \mathrm{dez}$. 2018.

UOL. Futebol. Morumbi. Jornal Uol . Disponível em: $<$ https://esporte.uol.com.br/futebol/ultimasnoticias/lancepress/2018/12/25/teloes-iluminacao-vestiarios-saiba-maissobre-o-morumbi-2019.htm>. Acesso em: o1. fev. 2019.

UOL. População negra representa $54 \%$ da população do país mas são apenas $17 \%$ dos mais ricos. Jornal Uol Disponível em: <https://economia.uol.com.br/noticias/redacao/2015/12/o4/negrosrepresentam-54-da-populacao-do-pais-mas-sao-so-17-dos-maisricos.htm"populacao-do-pais-mas-sao-so-17-dos-mais-ricos.htm>. Acesso em: 21 nov. 2018. 